\title{
Malignant mesothelioma: attributable risk of asbestos exposure
}

Robert Spirtas, Ellen F Heineman, Leslie Bernstein, Gilbert W Beebe, Robert J Keehn, Alice Stark, Bernard L Harlow, Jacques Benichou

\begin{abstract}
Objectives-To evaluate a case-control study of malignant mesothelioma through patterns of exposure to asbestos based upon information from telephone interviews with next of kin.
\end{abstract}

Methods-Potential cases, identified from medical files and death certificates, included all people diagnosed with malignant mesothelioma and registered during 1975-1980 by the Los Angeles County Cancer Surveillance Program, the New York State Cancer Registry (excluding New York City), and 39 large Veterans Administration hospitals. Cases whose diagnosis was confirmed in a special pathology review as definite or probable mesothelioma $(n=208)$ were included in the analysis. Controls $(n=533)$ had died of other causes, excluding cancer, respiratory disease, suicide, or violence. Direct exposure to asbestos was determined from responses to three types of questions: specific queries as to any exposure to asbestos; occupational or non-vocational participation in any of nine specific activities thought to entail exposure to asbestos; and analysis of lifetime work histories. Indirect exposures were assessed through residential histories and reported contact with family members exposed to asbestos.

Results-Among men with pleural mesothelioma the attributable risk (AR) for exposure to asbestos was $88 \%(95 \%$ confidence interval (95\% CI) 76-95\%). For men, the AR of peritoneal cancer was $58 \%$ (95\% CI 20-89\%). For women (both sites combined), the AR was $23 \%(95 \%$ CI 3-72\%). The large differences in AR by sex are compatible with the explanations: a lower background incidence rate in women, lower exposure to asbestos, and greater misclassification among women.

Conclusions-Most of the pleural and peritoneal mesotheliomas in the men studied were attributable to exposure to asbestos. The situation in women was less definitive.

(Occup Environ Med 1994;51:804-811)

Keywords: asbestos, epidemiological factors, mesothelioma, occupational exposure, peritoneal, pleural
The incidence of mesothelioma has been increasing throughout the industrialised world. $^{1-10}$ The overall upward trend in incidence of mesothelioma in the United States from $1974-1990$ is primarily due to increased incidence among men. ${ }^{11}$ Although asbestos exposure is generally accepted as the primary cause of this tumour, other agents are suspected of causing or promoting mesothelioma in experimental studies of animals. ${ }^{12-14} \mathrm{~A}$ review of the scientific literature on animals and humans indicated that a significant proportion of mesotheliomas may be due to factors other than exposure to asbestos. ${ }^{14}$ In this paper, we estimate the proportion of mesothelioma cases in the United States diagnosed between 1975 and 1980 that can be attributed to asbestos, and compare the proportions of mesotheliomas explained by four different measures of exposure.

\section{Materials and methods}

STUDY SAMPLE

Potential cases were identified from the New York State Health Department Cancer Registry, the Los Angeles County Cancer Surveillance Program, and 39 large Veterans Administration hospitals, and were diagnosed between 1 January, 1975 and 31 December, 1980. Those from Los Angeles County and New York State (population based cancer registries) included all incident cases whose registry files (including hospital, clinical, pathology, and death certificate reports) mentioned the word mesothelioma; and from the Veterans Administration hospitals all pleural and peritoneal mesothelioma cases for whom pathology slides or tissues were available for study. For the Veterans Administration, pathology services at individual hospitals selected potential cases in response to a letter sent from the pathology service in the Veterans Administration Central Office.

Telephone interviews were conducted with the next of kin of eligible cases and controls, between 1982 and 1984 . Of the 720 eligible cases, next of kin of $536(75 \%)$ were successfully interviewed and 184 respondents (25\%) were not interviewed: 106 were not located, 64 refused to be interviewed, eight were not approached due to refusal by the physician to allow contact, and six had partially completed interviews. Of these 536 
completed interviews, 208 pleural or peritoneal cancers were confirmed by an expert pathology review (see next section) as definite or probable mesotheliomas. These 208 confirmed cases form the case group for this study.

Controls were selected from people who died of causes other than cancer, respiratory disease, suicide, or violence. Cancer and respiratory disease were excluded because several cancers and respiratory diseases may be related to asbestos exposure. ${ }^{15}$ Suicide and violence were omitted because of concern for the potential trauma involved in interviewing next of kin of people who died from violent deaths. Controls from New York State and Los Angeles County were selected from death certificate files. Controls from the Veterans Administration were selected from deaths in the beneficiary identification and records location subsystem (BIRLS), a computerised file of veterans who received medical and financial benefits. The controls from the Veterans Administration are representative of all veterans who have sought benefits from the Veterans Administration. Originally, pair matched controls (matched to cases on date of birth, race, sex, year of death, and county of residence (New York State, Los Angeles County) or hospital (Veterans Administration) had been selected for the 208 confirmed cases who were used in the analysis. A larger group of controls was available, however, the 678 eligible controls were matched to the original 720 eligible cases (before review of histological slides). Of these 678 , next of kin of $533(79 \%)$ were interviewed, and 145 respondents $(21 \%)$ were not interviewed: 138 were not located, four had partially completed interviews, and three refused.

To take advantage of the information available from the controls matched to unconfirmed cases, these 533 subjects were used in the analysis as the control group. Adjustment for age, geographic area, and smoking by stratification and logistic regression, rather than with a matched analysis, enabled us to control confounding while maximising precision. ${ }^{1617}$

\section{INTERVIEWS}

For each deceased case or control, the next of kin listed on the death certificate was contacted by letter and telephone to identify an appropriate respondent. The sequence of preferred respondents was spouse, child, sibling, other relative, or friend. One living case self responded. Four questionnaires ${ }^{18-21}$ were reviewed in developing the instrument used for this study. The telephone interview solicited information on lifetime exposures to chemical and physical agents, disease history, smoking history, and demographic background.

Potential direct exposure to asbestos was defined in three ways based on interview data: (a) ever or never, according to the response to the question: "Was the study subject ever exposed to asbestos?"; (b) by any one or a combination of nine predetermined occupational or non-vocational activities in which asbestos exposure was thought likely (brake lining installation or repair, furnace or boiler installation or repair, building demolition, plumbing or heating repair, insulation work, shipbuilding, ship demolition, or shipyard work, elevator installation or repair, textile production, and paper production); and (c) by job-exposure matrix, based on lifetime work histories. For the job-exposure matrix, each job held by a subject was classified as involving none, $<10 \%, 10-19 \%, 20-49 \%$, or $\geqslant 50 \%$ likelihood of asbestos exposure, according to the results of the National Institute for Occupational Safety and Health (NIOSH) National Occupational Hazard Survey (NOHS). ${ }^{22}$ The NOHS reported estimates of proportions of workers exposed to a variety of physical and chemical agents, based on walk through surveys by industrial hygienists of about 5000 non-agricultural businesses in 67 metropolitan areas conducted in 1972-4. NIOSH provided tables (Pederson, personal communication, 1982) which categorised likelihood of asbestos exposure for combinations of four digit 1972 standard industrial classification (SIC) industry $\operatorname{codes}^{23}$ and three-digit 1970 census occupation codes. $^{24}$ We converted these categories to three-digit 1980 census industry and threedigit 1980 census occupation $\operatorname{codes}^{25}$ to be compatible with the data files for the current study. Each study subject was classified into the highest achieved exposure category (without consideration of time weighting) based on the NOHS estimate for the entire work history. Indirect exposure was measured by questions about residence of study subject and exposures of cohabitants.

\section{PATHOLOGY REVIEW}

All available pathology material was initially reviewed by pathologists, one of whom was chosen by each of the three participating study centres. No review was possible for 110 of the interviewed cases, due to lack of pathology material. The standard five category system was used for recording the certainty of malignant mesothelioma (definite, probable, possible, unlikely, not mesothelioma). ${ }^{26}$ As differences were noted among the three study centres in the percentage of potential cases judged to be true mesotheliomas, a more extensive pathological review of a sample of cases was conducted by a panel composed of five pathologists: the original three pathologists from the three study centres plus two referee pathologists recognised internationally as expert in the diagnosis of mesothelioma. Based on the results of this panel review, ${ }^{27}$ and to assure consistency of diagnosis, it was decided to have all slides re-reviewed by the two referee pathologists. Only the 208 cases deemed definite or probable mesotheliomas in the final expert review were included in this analysis.

\section{STATISTICAL METHODS}

Crude and stratified odds ratios (ORs) and 
$95 \%$ confidence intervals ( $95 \%$ CIs), controlled for age in four categories, geographic area, and cigarette smoking (ever or never), were calculated for the association of each index of exposure and mesothelioma. We controlled for smoking because it confounded the association of mesothelioma and asbestos exposure (controls were more likely than cases to have been cigarette smokers and to have died of tobacco related causes). Six subjects without information on smoking were excluded from the analyses. The maximum likelihood method was used to estimate the OR and the method of Cornfield as modified by $\operatorname{Gart}^{28} 29$ was used to estimate 95\% CIs. Tests for trend over duration of exposure were conducted with the method of Mantel. ${ }^{30}$

For calculations of ORs and attributable risks, the unexposed group (never exposed) was defined as those subjects with no reported exposure to asbestos, none of the nine specified activities, no jobs with NOHS likelihood of exposure $>0$, no cohabitants with asbestos exposure, and no residence within two miles of an asbestos mine or mill. Blank responses to questions on exposure were treated as if the subject was not exposed, based on our judgment that such a response was closer to a negative answer.

Attributable risk (AR) was defined as the proportion of disease burden that can be related to asbestos exposure. Adjusted overall and partial ARs for asbestos and corresponding $95 \%$ CIs were based on a computed unconditional logistic regression. ${ }^{31}{ }^{32}$ The models controlled for the main effects and interactions of age (four levels), geographic area, and sex, and for the main effect of smoking (ever or never). Age, area, and sex specific models, of course, omitted the respective covariate. The overall AR compared those never exposed with the remaining subjects, exposed by any measure of exposure to asbestos. Partial ARs were calculated to evaluate the proportion of mesothelioma related to the individual measures of asbestos. Partial $A R$ is defined as the proportion of disease burden that can be related to asbestos exposure captured by the particular measure. For the partial ARs, three categories of exposure had to be considered in the model; subjects exposed to the measure of interest, those never exposed, and those neither exposed to that measure nor unexposed. Thus, each logistic model included two dummy variables (one for the measure of interest, and another for any other exposure to asbestos) and yielded an OR for the exposure of interest adjusted for covariates and the other measures of asbestos exposure. The prevalence for each AR was the proportion of cases exposed by the measure of interest compared with the total number of cases. For the NOHS classification, four categories, including two exposed levels (1-19\% likelihood, and 20-99\% likelihood), never exposed, and those neither exposed nor not exposed were considered in the computation of partial ARs.

\section{Results}

Of the 208 cases that were confirmed as definite or probable mesothelioma, 183 (162 men, 21 women) were classified as pleural or pleural and peritoneal, and 25 (21 men, four women) were classified as peritoneal only. Table 1 shows the demographic characteristics of the cases and controls. Most cases and controls were white men $(86 \%$ of cases, $76 \%$ of controls). Sixty five per cent of cases and $75 \%$ of controls were past or current cigarette smokers (not shown in table). Next of kin respondents were primarily spouses $(55 \%$ of cases and $47 \%$ of controls), sons or daughters ( $24 \%$ of cases and $27 \%$ of controls), and siblings ( $7 \%$ of cases and $12 \%$ of controls). The remaining respondents were other relatives, friends, and one self reporting case. All Veterans Administration cases were men and tended to be older at diagnosis than cases from New York State or Los Angeles County.

Table 2 shows the number and percentage of cases and controls exposed to asbestos. More next of kin of cases than of controls said

Table 1 Demographic characteristics of cases and controls, by geographic location

\begin{tabular}{|c|c|c|c|c|c|c|}
\hline & \multicolumn{2}{|c|}{ New York State } & \multicolumn{2}{|c|}{ Los Angeles County } & \multicolumn{2}{|c|}{ Veterans Administration } \\
\hline & Cases & Controls & Cases & Controls & Cases & Controls \\
\hline & $\begin{array}{l}n(\%) \\
95(100 \cdot 0)\end{array}$ & $\begin{array}{l}n(\%) \\
287(100 \cdot 0)\end{array}$ & $\begin{array}{l}n(\%) \\
79(100 \cdot 0)\end{array}$ & $\begin{array}{l}n(\%) \\
176(100 \cdot 0)\end{array}$ & $\begin{array}{l}n(\%) \\
34(100 \cdot 0)\end{array}$ & $\begin{array}{l}n(\%) \\
70(100 \cdot 0)\end{array}$ \\
\hline $\begin{array}{c}\text { Age at death: } \\
<50 \\
50-59 \\
60-69 \\
70-79 \\
80+ \\
\text { Unknown }\end{array}$ & $\begin{array}{rr}4 & (4 \cdot 2) \\
22 & (23 \cdot 2) \\
35 & (36 \cdot 8) \\
24 & (25 \cdot 3) \\
2 & (2 \cdot 1) \\
8 & (8 \cdot 4)\end{array}$ & $\begin{array}{r}26(9 \cdot 1) \\
51(17 \cdot 8) \\
101(35 \cdot 2) \\
67(23 \cdot 3) \\
4(1 \cdot 4) \\
38(13 \cdot 2)\end{array}$ & $\begin{array}{r}5(6 \cdot 3) \\
15(19 \cdot 0) \\
26(32 \cdot 9) \\
20(25 \cdot 3) \\
1(1 \cdot 3) \\
12(15 \cdot 2)\end{array}$ & $\begin{array}{l}17(9 \cdot 7) \\
30(17 \cdot 0) \\
53(30 \cdot 1) \\
39(22 \cdot 2) \\
37(21 \cdot 0)\end{array}$ & $\begin{array}{r}8(23 \cdot 5) \\
11(32 \cdot 4) \\
7(20 \cdot 6) \\
8(23 \cdot 5)\end{array}$ & $\begin{array}{r}2(2 \cdot 9) \\
18(25 \cdot 7) \\
31(44 \cdot 3) \\
6(8 \cdot 6) \\
13(18 \cdot 6)\end{array}$ \\
\hline \multicolumn{7}{|c|}{ Race and sex groups ${ }^{\star}$} \\
\hline $\begin{array}{l}\text { White M } \\
\text { Non-white M } \\
\text { White F }\end{array}$ & $\begin{array}{l}78(82 \cdot 1) \\
17(17 \cdot 9)\end{array}$ & $\begin{array}{r}203(70 \cdot 7) \\
2(0 \cdot 7) \\
78(27 \cdot 2)\end{array}$ & $\begin{array}{r}69(87 \cdot 3) \\
1(1 \cdot 3) \\
8(10 \cdot 1)\end{array}$ & $\begin{array}{r}139(79 \cdot 0) \\
7(4 \cdot 0) \\
27(15 \cdot 3)\end{array}$ & $\begin{array}{r}32(94 \cdot 1) \\
2(5 \cdot 9)\end{array}$ & $\begin{array}{r}64(91 \cdot 4) \\
4(5 \cdot 7)\end{array}$ \\
\hline
\end{tabular}

* Of the five non-white women who were originally diagnosed as having mesothelioma, only one completed the questionnaire. This case was not confirmed as having mesothelioma and was not included in the analysis. Not listed are one case and nine controls with unknown race. 
Table 2 Frequency and percentages of cases and controls with reported exposure to asbestos

\begin{tabular}{|c|c|c|}
\hline & \multirow{2}{*}{$\begin{array}{l}\text { Cases } \\
n(\%) \\
208(100 \cdot 0)\end{array}$} & \multirow{2}{*}{$\begin{array}{l}\text { Controls } \\
n(\%) \\
533(100 \cdot 0)\end{array}$} \\
\hline & & \\
\hline Ever exposed to asbestos & $129(62 \cdot 0)$ & $90(16 \cdot 9)$ \\
\hline $\begin{array}{l}\text { Ever performed: } \\
\text { Brake lining work or repair } \\
\text { Furnace or boiler installation or } \\
\text { repair } \\
\text { Building demolition } \\
\text { Plumbing or heating } \\
\text { Insulation } \\
\text { Shipbuilding or yard or repair } \\
\text { Elevator installation or repair } \\
\text { Production of textiles } \\
\text { Production of paper products } \\
\text { At least one of these nine }\end{array}$ & $\begin{array}{r}33(15 \cdot 8) \\
\\
51(24 \cdot 5) \\
11(5 \cdot 3) \\
72(34 \cdot 6) \\
83(39 \cdot 9) \\
67(32 \cdot 2) \\
5(2 \cdot 4) \\
4(1.9) \\
7(3.4) \\
150(72 \cdot 1)\end{array}$ & $\begin{array}{r}72(13 \cdot 5) \\
\\
39(7 \cdot 3) \\
29(5 \cdot 4) \\
125(23 \cdot 5) \\
83(15 \cdot 6) \\
40(7.5) \\
5(0.9) \\
20(3.8) \\
21(3.9) \\
238(44 \cdot 7)\end{array}$ \\
\hline $\begin{array}{l}\text { Highest likelihood of exposure by } \\
\text { job history and NOHS }{ }^{\star}(\%): \\
0 \\
1-9 \\
10-19 \\
20-49 \\
\geqslant 50\end{array}$ & $\begin{array}{r}110(52 \cdot 9) \\
42(20 \cdot 2) \\
2(1 \cdot 0) \\
41(19 \cdot 7) \\
13(6 \cdot 3)\end{array}$ & $\begin{array}{r}372(69 \cdot 8) \\
99(18.6) \\
10(1.9) \\
40(7.5) \\
12(2.3)\end{array}$ \\
\hline Cohabitant ever exposed & $16(7 \cdot 7)$ & $24(4 \cdot 5)$ \\
\hline Cohabitant any of nine activities & $37(17 \cdot 8)$ & $93(17 \cdot 4)$ \\
\hline $\begin{array}{l}\text { Lived within two miles of asbestos } \\
\text { mine or mill }\end{array}$ & $0(0.0)$ & $8(1 \cdot 5)$ \\
\hline $\begin{array}{l}\text { Overall reported exposure } \\
\text { Potential } \\
\text { No known exposure }\end{array}$ & $\begin{array}{l}\text { ost: } \\
186(89 \cdot 4) \\
22(10 \cdot 6)\end{array}$ & $\begin{array}{l}335(62 \cdot 9) \\
198(37 \cdot 1)\end{array}$ \\
\hline
\end{tabular}

^For each study subject, highest likelihood of exposure was assigned based upon NOHS categorisation of all jobs (see Methods section)

†Potential exposure $=$ reports ever exposed to asbestos, any of the nine specified activities, at least one job with NOHS likelihood $>0$, cohabitants with asbestos exposure, or residence within two miles of asbestos mill.

No known exposure $=$ reports never exposed to asbestos, none of the nine specified activities, no jobs with NOHS

likelihood $>0$, no cohabitants with asbestos exposure, and no residence with two miles of asbestos mine or mill. the study subject was ever exposed to asbestos, gave a positive response to questions on occupational or non-vocational exposure to any of the nine activities involving suspected asbestos exposure, or were classified by the NOHS as being employed in a job with $>0 \%$ likelihood of asbestos exposure. Reports of ever living within two miles of an asbestos mine or mill were similar for cases and controls. No known source of asbestos exposure was reported for 22 cases (11\%) and 198 $(37 \%)$ controls.

Table 3 shows ORs and $95 \%$ CIs for the risk of mesothelioma from exposure to asbestos by sex, age, and tumour site (men only). The ORs were nearly an order of magnitude higher for men than for women for all measures of asbestos exposure. None of the ORs among women was significantly different from unity, but female cases were few. Among men, pleural mesothelioma was more strongly associated with asbestos exposure than was peritoneal mesothelioma. Among the measures of asbestos exposure, the question, "Was the study subject ever exposed to asbestos?", generally yielded higher ORs than the other measures, followed by the subgroup of jobs for which the likelihood of exposure to asbestos was at least $20 \%$. When ORs for age at death $<65$ and $\geqslant 65$ were compared, there were no important differences. Many subjects had multiple activities involving asbestos exposure. For example, among subjects with brake lining installation or repair history, 33\% also had shipbuilding or shipyard work and $55 \%$ had performed insulation work. For this

Table 3 Odds ratios (95\% CIs) for the association of asbestos exposure with malignant mesothelioma, by sex, age, and by tumour site for men *

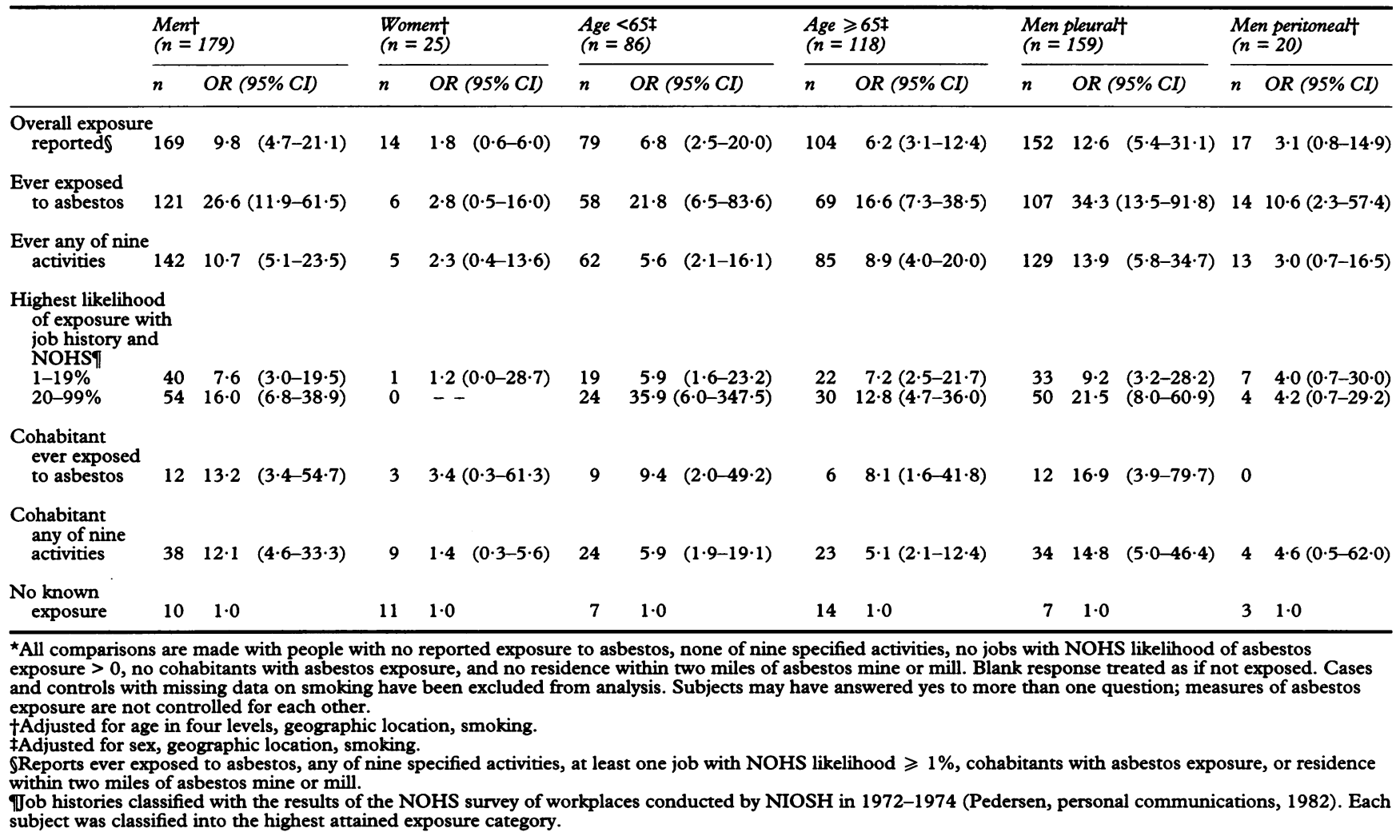


Table 4 Adjusted odds ratios (95\% CI) for the association of asbestos exposure with pleural malignant mesothelioma among men, by duration, latency, age at first exposure, decade of first exposure, and decade of last exposure*

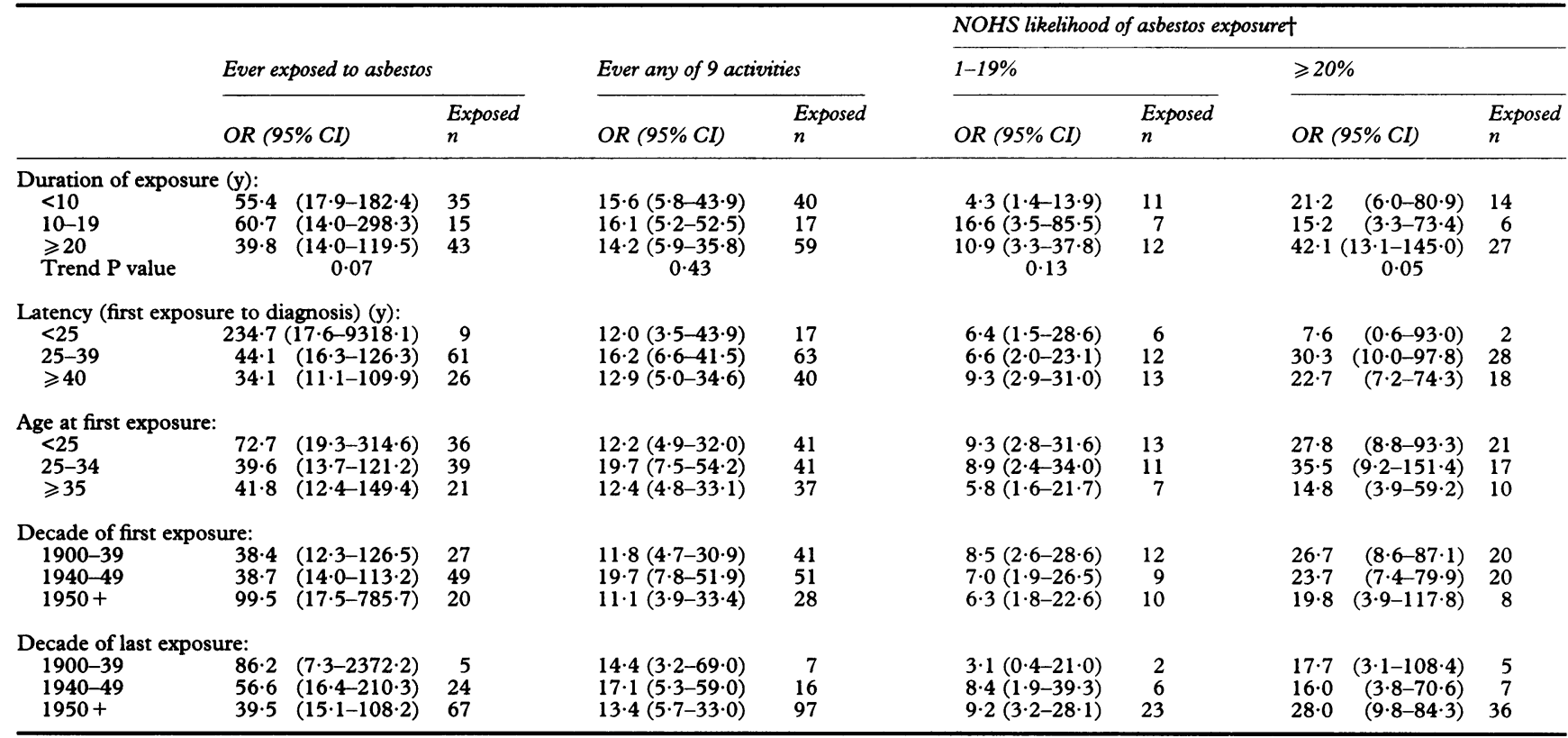

^All comparisons are made with people with no reported exposure to asbestos, none of nine specified activities, no jobs with NOHS likelihood of asbestos exposure $>0$, no cohabitants with asbestos exposure, and no residence within two miles of asbestos mine or mill. Odds ratios adjusted for age and smoking. Cases and controls with missing data on smoking were excluded. $P$ value based on Mantel trend test. ${ }^{29}$

†For each study subject, highest likelihood of exposure was assigned based upon NOHS categorisation of all jobs. (Pederson D, personal communication 1982).

reason, results are not presented individually for each of the nine activities.

For the three methods of classifying asbestos exposure, table 4 shows patterns of risk of pleural mesothelioma among men by duration, latency, age at first exposure, and decade of first and last exposure. Dates when first and last exposed for each measure were obtained from reported start and stop dates for jobs held by the subject, or from dates during which the subject lived with a cohabitant who was reportedly exposed. Reported asbestos exposure that was related to neither job nor cohabitant lacked dates and thus could not be considered in these analyses. The measures of exposure in table 4 are not controlled for each other. Patterns of risk with latency, age at first exposure, and decades of first and last exposure were similar among different durations of exposure categories (not shown). Although risk of mesothelioma is increased in all categories for every measure, patterns differ between measures. Risk decreases with length of reported exposure to asbestos for the ever exposed to asbestos category, is unchanged with time engaged in the nine suspect activities, and is inconsistent with time in jobs judged to have $1-19 \%$ or $\geqslant 20 \%$ likelihood of exposure to asbestos. Only the increase with duration of exposure in the $\geqslant 20 \%$ likelihood category is significant.

Responses to the ever or never exposed to asbestos question yielded the highest risk (OR $=234 \cdot 7,95 \%$ CI 17.6-9318.1) among subjects most recently exposed, and lower risks with longer latent periods. In contrast, risks were similar for all intervals since first exposure to any of the nine activities, and higher for longer latency periods for the two likeli- hood categories. The ORs based on the nine suspected activities gave inconsistent results for age at first exposure. According to the ever or never question, the risk was higher with younger age at first exposure. For both categories of likelihood of asbestos exposure, subjects had lower risks if they were exposed after the age of 35 , but the pattern was not consistent in younger age groups.

Results by decade of first exposure were complementary to those for latency, with the two likelihood measures showing higher risks for subjects exposed earlier, and the ever or never questions showing highest risk among subjects beginning exposure most recently. Risks were not relatively higher for first exposure during the 1940s, except for those subjects who were involved in at least one of the nine suspect activities. Of the men with pleural mesothelioma $70-80 \%$ were judged to have been still exposed in the 1950s and later by each of the measures of asbestos exposure. Risk patterns were inconsistent across categories of decade of last exposure by the different measures.

Table 5 shows the overall AR of mesothelioma that can be related to asbestos and partial ARs for each individual measure of exposure. Among men, pleural mesothelioma was associated with higher ARs than was peritoneal mesothelioma. A substantially smaller percentage of the cases among women were attributable to asbestos, both overall (AR = 22.5) and for individual measures of exposure. Except for the ever or never question, ARs for women were not detectably different from zero. Overall and partial ARs were higher among the all male Veterans Administration population than among the New York State or Los Angeles County total 
Table 5 Percentage of overall and partial attributable risk (95\% CIs) of malignant mesothelioma due to asbestos exposure by geographic location, site, sex, and age

\begin{tabular}{|c|c|c|c|c|c|c|c|c|c|}
\hline & $\begin{array}{l}\text { New } \\
\text { York } \\
\text { State } \dagger \\
(n=94)\end{array}$ & $\begin{array}{l}\text { Los } \\
\text { Angeles } \\
\text { Countyt } \\
(n=76)\end{array}$ & $\begin{array}{l}\text { Veterans } \\
\text { Administration } \dagger \\
(n=34)\end{array}$ & $\begin{array}{l}M e n^{\star} \\
(n=179)\end{array}$ & $\begin{array}{l}\text { Women } \ddagger \\
(n=25)\end{array}$ & $\begin{array}{l}<659 \\
(n=86)\end{array}$ & $\begin{array}{l}\geqslant 650 \\
(n=118)\end{array}$ & $\begin{array}{l}\text { Men } \\
\text { pleuralt } \\
(n=159)\end{array}$ & $\begin{array}{l}\text { Men } \\
\text { peritoneal } \$ \\
(n=20)\end{array}$ \\
\hline $\begin{array}{l}\text { Attributable risk risk f } \\
\text { Overall exposure } \\
\text { reportedף }\end{array}$ & $\begin{array}{l}\text { or asbestos: } \\
68 \cdot 1 \\
(49 \cdot 3-87 \cdot 4)\end{array}$ & $\begin{array}{l}78 \cdot 5 \\
(56 \cdot 9-91 \cdot 0)\end{array}$ & $\begin{array}{l}86 \cdot 3 \\
(54 \cdot 1-97 \cdot 1)\end{array}$ & $\begin{array}{l}84 \cdot 7 \\
(72 \cdot 5-92 \cdot 1)\end{array}$ & $\begin{array}{l}22 \cdot 5 \\
(3 \cdot 2-71 \cdot 7)\end{array}$ & $\begin{array}{l}73 \cdot 1 \\
(46 \cdot 8-89 \cdot 4)\end{array}$ & $\begin{array}{l}73 \cdot 6 \\
(57 \cdot 6-85 \cdot 1)\end{array}$ & $\begin{array}{l}88 \cdot 0 \\
(75 \cdot 5-94 \cdot 5)\end{array}$ & $\begin{array}{l}58 \cdot 1 \\
(19 \cdot 7-88 \cdot 7)\end{array}$ \\
\hline $\begin{array}{l}\text { Partial attributable ris } \\
\text { Ever exposed to } \\
\text { asbestos } \\
\text { Ever any of nine } \\
\text { activities }\end{array}$ & $\begin{array}{l}\text { ks: } \\
50 \cdot 2 \\
(39 \cdot 0-61 \cdot 4) \\
54 \cdot 9 \\
(40 \cdot 2-68 \cdot 7)\end{array}$ & $\begin{array}{l}69 \cdot 0 \\
(56 \cdot 1-79 \cdot 4) \\
67 \cdot 7 \\
(49 \cdot 7-81 \cdot 6)\end{array}$ & $\begin{array}{l}59 \cdot 2 \\
(40 \cdot 8-75 \cdot 3) \\
65 \cdot 9 \\
(45 \cdot 0-82 \cdot 0)\end{array}$ & $\begin{array}{l}65 \cdot 3 \\
(57 \cdot 4-72 \cdot 4) \\
71 \cdot 8 \\
(61 \cdot 6-80 \cdot 1)\end{array}$ & $\begin{array}{l}14 \cdot 4 \\
(2 \cdot 7-50 \cdot 5) \\
7 \cdot 0 \\
(0 \cdot 2-73 \cdot 2)\end{array}$ & $\begin{array}{l}62 \cdot 7 \\
(47 \cdot 8-75 \cdot 8) \\
52 \cdot 8 \\
(32 \cdot 8-72 \cdot 0)\end{array}$ & $\begin{array}{l}55 \cdot 2 \\
(45 \cdot 2-64 \cdot 8) \\
61 \cdot 9 \\
(49 \cdot 1-73 \cdot 3)\end{array}$ & $\begin{array}{l}65 \cdot 5 \\
(57 \cdot 2-72 \cdot 8) \\
75 \cdot 2 \\
(64 \cdot 9-83 \cdot 2)\end{array}$ & $\begin{array}{l}63 \cdot 5 \ddagger \ddagger \\
(37 \cdot 2-83 \cdot 6) \\
43 \cdot 9 \\
(14 \cdot 7-78 \cdot 1)\end{array}$ \\
\hline $\begin{array}{l}\text { Highest likelihood of } \\
\text { exposure from job } \\
\text { history and NOHS: } \\
1-19 \% \\
20-99 \%\end{array}$ & $\begin{array}{l}15 \cdot 7 \\
(8 \cdot 3-27 \cdot 8) \\
23 \cdot 7 \\
(15 \cdot 5-34 \cdot 5)\end{array}$ & $\begin{array}{l}14 \cdot 9 \\
(7 \cdot 5-27 \cdot 2) \\
19 \cdot 4 \\
(11 \cdot 6-30 \cdot 7)\end{array}$ & $\begin{array}{l}17 \cdot 5 \\
(7 \cdot 0-37 \cdot 6) \\
36 \cdot 5 \\
(21 \cdot 5-54 \cdot 6)\end{array}$ & $\begin{array}{l}19 \cdot 1 \\
(13 \cdot 2-26 \cdot 8) \\
28 \cdot 4 \\
(21 \cdot 9-35 \cdot 9)\end{array}$ & t & $\begin{array}{l}14 \cdot 6 \\
(5 \cdot 9-31 \cdot 8) \\
25 \cdot 4 \\
(15 \cdot 3-39 \cdot 2)\end{array}$ & $\begin{array}{l}14 \cdot 9 \\
(8 \cdot 6-24 \cdot 4) \\
22 \cdot 9 \\
(15 \cdot 6-32 \cdot 3)\end{array}$ & $\begin{array}{l}18 \cdot 2 \\
(12 \cdot 3-26 \cdot 1) \\
30 \cdot 1 \\
(23 \cdot 1-38 \cdot 0)\end{array}$ & $\begin{array}{l}26 \cdot 1 \\
(8 \cdot 7-56 \cdot 7) \\
14 \cdot 7 \\
(3 \cdot 4-45 \cdot 4)\end{array}$ \\
\hline $\begin{array}{l}\text { Cohabitant ever } \\
\text { exposed }\end{array}$ & $\begin{array}{l}5 \cdot 2 \\
(1 \cdot 9-13 \cdot 5)\end{array}$ & $\begin{array}{l}8 \cdot 4 \\
(3 \cdot 7-18 \cdot 0)\end{array}$ & $\begin{array}{l}5 \cdot 8 \\
(1 \cdot 4-20 \cdot 9)\end{array}$ & $\begin{array}{l}6 \cdot 3 \\
(3 \cdot 4-11 \cdot 1)\end{array}$ & $\begin{array}{l}7 \cdot 9 \\
(1 \cdot 0-42 \cdot 4)\end{array}$ & $\begin{array}{l}5 \cdot 1 \\
(1 \cdot 3-18 \cdot 8)\end{array}$ & $\begin{array}{l}4 \cdot 5 \\
(1 \cdot 9-10 \cdot 8)\end{array}$ & $\begin{array}{l}7 \cdot 2 \\
(4 \cdot 0-12 \cdot 6)\end{array}$ & $t$ \\
\hline $\begin{array}{l}\text { Cohabitant any of } \\
\text { nine activities }\end{array}$ & $\begin{array}{l}16 \cdot 5 \\
(8 \cdot 6-29 \cdot 4)\end{array}$ & $\begin{array}{l}18 \cdot 1 \\
(9 \cdot 6-31 \cdot 4)\end{array}$ & $\begin{array}{l}22 \cdot 7 \\
(11 \cdot 3-40 \cdot 2)\end{array}$ & $\begin{array}{l}18 \cdot 9 \\
(13 \cdot 3-26 \cdot 1)\end{array}$ & $\begin{array}{l}7 \cdot 0 \\
(0 \cdot 1-92 \cdot 5)\end{array}$ & $\begin{array}{l}23 \cdot 5 \\
(12 \cdot 0-40 \cdot 8)\end{array}$ & $\begin{array}{l}15 \cdot 7 \\
(9 \cdot 2-25 \cdot 3)\end{array}$ & $\begin{array}{l}19 \cdot 5 \\
(13 \cdot 6-27 \cdot 1)\end{array}$ & $\begin{array}{l}13 \cdot 6 \\
(2 \cdot 8-45 \cdot 9)\end{array}$ \\
\hline
\end{tabular}

*Attributable risk \% calculated with an approach based on logistic regression (see Methods section). All comparisons are made with people with no reported exposure to asbestos, none of nine specified activities, no jobs with NOHS likelihood of asbestos exposure $>0$, no cohabitants with asbestos exposure, and no residence within two miles of asbestos mine or mill. Cases and controls with missing data on

†Adjusted for age, sex (except Veterans Administration where all subjects were men) and smoking status.

†Adjusted for age, smoking status, and geographic area.

Adjusted for age, sex, smoking status, and geographic area

TReports ever exposed to asbestos, any of nine specified activities, at least one job with NOHS likelihood $\geqslant 1 \%$, cohabitants with asbestos

exposure, or residence within two miles of asbestos mine or mill.

For each study subject, highest likelihood of exposure was assigned based on NOHS categorisation of all jobs (see Methods section).

$\star \star$ Attributable risks not presented; unreliable because only one exposed case.

HAttributable risks not presented; no exposed cases.
HPartial attributable risk is greater than overall attributable risk because the odds ratio in intermediate category in logistic model, neither ever exposed by this measure nor never exposed, was $<1$.

populations, but are comparable with those for all men in the study. For cases $<65$ years old ARs are consistently higher than for cases $\geqslant 65$, but there is considerable overlap in $95 \%$ CIs.

\section{Discussion}

Previous estimates of the percentage of cases of mesothelioma that had had asbestos exposure have varied from $13-100 \% .^{3182033-60}$ Among these studies the paper by McDonald et $a^{45}$ provided a formal measure of risk attributable to type of asbestos fibre. No other study gave any measure of attributable risk. The results of our study found the overall AR to be highest among male pleural cases, which is also the group with greatest frequency of asbestos exposure. Previous analyses of incidence and of mortality from mesothelioma found the highest rates and increasing trends for older men with pleural mesothelioma. ${ }^{86162}$ Enterline and Henderson studied United States death rates for malignant neoplasms of the pleura (the disease classification closest to mesothelioma of the pleura) during the years 1968-81.62 They found an increase in death rates for men aged $>65$, but not for younger men or for women. We found slightly, but generally higher partial ARs among the younger male cases. There may have been better reporting by respondents for younger cases. Also, very high exposures, which were likely to have occurred in the 1930 s and 1940 s, may have resulted in lung cancer or asbestosis before mesothelioma could develop.
Studies that showed a high percentage of cases exposed to asbestos $(>80 \%)$ have tended to come from geographic areas near shipyards 3551525758 or crocidolite asbestos mines. ${ }^{4656}$ In our study, $20 \%, 46 \%$, and $35 \%$ of the respondents for cases from New York State, Los Angeles County and the Veterans Administration reported exposure in shipyards, shipbuilding, or ship repair. The relatively high percentage of cases from Los Angeles County with shipyard exposure is consistent with the large shipyard industry in that area. Studies that reported a low percentage $(<30 \%)$ of mesothelioma cases exposed to asbestos have tended to come from geographic areas remote from a main source of asbestos exposure. ${ }^{4950}$ The ARs calculated from the two population based registries are likely to be representative of their geographic areas. Data from the Veterans Administration (all men), which were included for comparison, provided results that were similar to results for men from the two population based cancer registries. They are not representative, however, of an easily defined population and the BIRLS controls are likely to be more similar to all veterans than are the Veterans Administration cases, who may have lacked access to other medical care.

Mesothelioma was not significantly associated with asbestos exposure among women in our study, although the OR for ever exposed women was $2 \cdot 7$. Although over $50 \%$ of the female cases reported some exposure to asbestos, the number of female cases was small, and women were less likely than men to be employed in jobs expected to have the 
highest exposure to asbestos, such as shipbuilding and insulation work. It is generally accepted that $<10 \%$ of the workforce exposed to asbestos is female. ${ }^{63}$ Vianna and Polan, in a study restricted to women, reported a significant association with indirect exposure to asbestos (husband or father had occupational exposure; $O R=10$ for pleural and peritoneal cases combined). ${ }^{54}$ Our results are consistent with previous studies in suggesting that differences in incidence rates of mesothelioma by sex and geographic site may be due to differences in exposure to asbestos.

In a previous study of a cohort of asbestos insulation workers the incidence of mesothelioma increased with time since first exposure, but not age at first exposure. ${ }^{20}$ For most measures we found ORs were higher for younger ages at first exposure. The wide CIs around the ORs for age at first exposure, indicate that our study has limited power to assess this issue. The relation between ORs and latency (time since first exposure) differed for the various measures of exposure. Results for the NOHS likelihood measures were consistent with previous findings, whereas those of the other two measures were not.

McDonald and McDonald described larger relative risks with selected occupations that have been associated with mesothelioma than by assigning probability of exposure to all jobs listed. ${ }^{18}$ Their controls consisted of people matched to given cases on age, sex, and year of death, and were restricted to people dying of pulmonary metastases from a non-pulmonary malignant tumour. They included a small group of jobs that had possible asbestos exposure as non-exposed in their analysis. In our study, the largest ORs come from the ever exposed question, then from the NOHS rating of the likelihood of asbestos exposure, which assigned probabilities of exposure to each job, for jobs where the probability of exposure to asbestos was $>20 \%$.

In our study, the definition of non-exposed was made as restrictive as possible and excluded any study subject ever exposed who had any of nine specified activities, any job with NOHS likelihood of exposure $>0$, ever cohabited with someone exposed to asbestos, or ever resident within two miles of an asbestos mine or mill. Because of the well known association between asbestos exposure and mesothelioma, there may have been reporting bias by next of kin of cases in responding to the question: "Was (study subject) ever exposed to asbestos?” Such a bias would result in artificially high estimates of $O R$ and $A R$.

All measures of asbestos exposure show the expected gradients in ORs for tumour site and sex. The NOHS, used to estimate likelihood of asbestos exposure in tables 2-5, was based on surveys conducted in 1972-74 and seemed not to have captured all exposures in the 1940 s to the 1960 s, the aetiologically meaningful period for our study, as noted by previous researchers. ${ }^{64}$ Also, it omitted subjects who performed some activities-for example, insulation work-outside work and lacked any measure of intensity. On the other hand, both the NOHS evaluation and involvement in the nine specified activities would be expected to include subjects with little or no exposure to asbestos. Such misclassification would tend to bias the estimates of risk toward the null.

None of these measures is ideal, as the next of kin could not be expected to recall all jobs and exposures for the study subject. ${ }^{6566}$ In particular, it is possible that exposures and jobs in the more distant past may have been missed. As none of the measures of asbestos exposure used in our study can be considered as the gold standard, it is impossible to measure sensitivity or specificity. Because of the presence of a large shipyard industry in the Los Angeles County area and the uniqueness of the Veterans Administration cases and controls, we do not consider these ARs to be directly representative of the whole population of the United States.

\section{Conclusions}

In our study nearly $90 \%$ of incidences of pleural mesothelioma among men were directly attributable to past exposures to asbestos. Although there were only a small number of peritoneal mesothelioma cases among men available for study, it seems that a substantial percentage of these cases, perhaps $60 \%$, also could be attributed to asbestos exposure. Among women, however, only about $20 \%$ of the cases were attributable to asbestos exposure. As the incidence of mesothelioma among women (about three cases per million women per year for all primary sites combined) is much lower than among men and has remained reasonably constant over time, it is possible that the incidence in women may be close to the background level. Alternatively, exposure to asbestos is lower and misclassification of exposure may be greater among women, which would also reduce their AR. Use of next of kin interviews may have resulted in biased responses. If time dulled the memories of next of kin of controls more than cases, the resulting ORs and ARs would be artificially inflated. The large percentage of cases first exposed in 1950 or later, argues for continued surveillance of future mesothelioma cases.

We thank Drs J C Wagner and L Hochholzer for review of histopathology slides.

1 Andersson $M$, Olsen $\mathrm{JH}$. Trend and distribution of mesothelioma in Denmark. $\mathrm{Br} f$ Cancer 1985.51: 699-705.

2 Bruckman L, Rubino RS, Christine B. Asbestos and mesothelioma incidence in Connecticut. Fournal of the Air Pollution Control Association 1977;27:121-6.

3 Churg A. Malignant mesothelioma in British Columbia in 1982. Cancer 1985;55:672-4.

4 Malker H, Weiner JA, McLaughlin JK. Register epidemiology studies of recent cancer trends in selected mology studies of recent cancer trends

5 Meijers JMM, Planteydt HT, Slangen JMM, et al. Trends and geographical patterns of pleural mesotheliomas in the Netherland 1970-87. Br F Ind Med 1990;47: 775-81.

6 Mowe G. The trend in incidence of malignant mesothelioma in Norway (1970-1979). Proceedings of the International Symposium on the Prevention of Occupational Cancer. Helsinki, 21-24 April 1981. Geneva: ILO, 1981. (Occupation Safety and Health Series No 46) 
7 Musk AW, Dolin PJ, Armstrong BK, et al. The incidence of malignant mesothelioma in Australia. Med $\mathcal{f}$ Aust 1989; 150:242-6.

8 Spirtas R, Beebe GW, Connelly RR, et al. Recent trends in mesothelioma incidence in the United States. $A m \mathcal{F}$ Ind Med 1986;9:397-407.

9 Walz R, Koch HK. Malignant pleural mesothelioma: some aspects of epidemiology, differential diagnosis and prog nosis. Pathol Res Pract 1990;186:124-34.

$10 \mathrm{Zwi}$ AB, Reid G, Landau SP, et al. Mesothelioma in South Africa, 1976-84: incidence and case characteristics. Int $\mathcal{F}$ Epidemiol 1989;18:320-9.

11 Miller BA, Ries LAG, Hankey BF, Kosary CL, Harras A, Devesa SS, Edwards BK, eds. SEER cancer statistics review: 1973-1990, National Cancer Institute. Bethesda: National Institute of Health, 1993. (NIH Pub No 932789.)

12 Stanton MF, Wrench C. Mechanisms of mesothelioma induction with asbestos and fibrous glass. 7 Natl Cancer Inst 1972;48:797-821.

13 Warren S, Brown CE, Chute RN, et al. Mesothelioma relative to asbestos, radiation, and methylcholanthrene. Arch Pathol Lab Med 1981;105:305-12.

14 Peterson JT, Greenberg SD, Buffler PA. Non-asbestosrelated malignant mesothelioma: a review. Cancer 1984 54:951-60.

15 International Agency for Research on Cancer. Overall Evaluation of Carcinogenicity: an updating of IARC monographs volumes 1-42. LARC Monogr Eval Carcinog Risks Hum Suppl 1987;7:106-8.

16 Prentice $R$. Use of the logistic model in retrospective studies. Biometrics 1976;32:599-606.

17 Schlesselman JJ. Case control studies: design, conduct, analysis. New York: Oxford University Press, 1982:272-5.

18 McDonald AD, McDonald JC. Malignant mesotheliom in North America. Cancer 1980;46:1650-6.

19 Peters GA, Peters BJ. Sourcebook on asbestos diseases: medical, legal, and engineering aspects, Vol 2. New York: Garland Law, 1986

20 Peto J, Seidman H, Selikoff IJ. Mesothelioma incidence among asbestos workers: implications for models of carcinogenesis and risk assessment calculations. $\mathrm{Br} f$ Cancer 1982;45:124-35.

21 Vianna NJ, Maslowsky J, Roberts S, et al. Malignant ianna NJ, Maslowsky J, Roberts S, et al. Malignant mesothelioma: epidemiologic pattern

22 National Occupational Hazard Survey, vol 3: survey analysis and supplemental tables. Cincinnati: National Institute fo Occupational Safety and Health. Department of Health Education, and Welfare, 1977. (Publication No 78-114.)

23 Technical Committee on Industrial Classification Standard industrial classification manual (1972). Washington: Executive Office of the President, Office of Management and Budget, US Government Printing Office, 1976-210-882/159.

24 US Bureau of the Census. 1970 Census of the population: alphabetical index of industries and occupations. alphabetical index of industries and occupation.

25 US Bureau of the Census. 1980 Census of the population: alphabetical index of industries and occupations. Washington: US Government Printing Office, 1981

26 Plantdeydt HT. Observer variation and reliability of the histopathological diagnosis of mesothelioma. Ann NY Acad Sci 1979;330:761-3.

27 Spirtas R, Keehn RJ, Beebe GW, et al. Results of a pathology review of recent US mesothelioma cases. Accomplishments in Oncology 1986;1:144-52.

28 Gart JJ. Point and interval estimation of the common odd ratio in the combination of $2 \times 2$ tables with fixed marginals. Biometrika 1970;57:471-5.

29 Thomas DG. Exact and asymptotic methods for the combination of $2 \times 2$ tables. Comput Biomed Res 1975;8. 423-46.

30 Mantel $\mathrm{N}$. Chi-square test with one degree of freedom: extension of the Mantel-Haenszel procedure. fournal of the American Statistical Association 1963;58:690-700.

31 Bruzzi P, Green SB, Byar DP, et al. Estimating the population attributable risk for multiple risk factors using

32 Benichou J, Gail MH. Variance calculations and confidence intervals for estimates of attributable risk based on logistic models. Biometrics 1990;46:991-1003.

33 Antman $\mathrm{KH}$, Blum RH, Greenberger JS, et al. Multimodality therapy for malignant mesothelioma based on a study of natural history. $\mathrm{Am} \mathcal{F}$ Med 1980;68: 356-62.

34 Armstrong BK, Musk W, Baker JE, et al. Epidemiology of malignant mesothelioma in Western Australia. Med $\mathcal{f}$ Aust 1984;141:86-8.

35 Ashcroft T. Epidemiological and quantitative relationships between mesothelioma and asbestos on Tyneside. $\mathcal{F}$ Clin
Pathol 1973;26:832-40.

36 Baris YI, Artivinli M, Sahin AA. Environmental mesothelioma in Turkey. Ann NY Acad Sci 1979;330:423-32.

77 Bignon J, Sebastien P, Di Menza L, Payan H. French mesothelioma register. Ann NY Acad Sci 1979;330: $455-66$.

38 Brenner J, Sordillo PP, Magill GB, Golbey RB. Malignant mesothelioma of the pleura. Cancer 1982;49. 2431-5.

39 Chahinian AP, Pajak TF, Holland JF, et al. Diffuse malig nant mesothelioma: prospective evaluation of 69 patients. Ann Intern Med 1982;96:746-55.

40 Elmes PC, McGaughey WT, Wade OC. Diffuse mesothelioma of the pleura and asbestos. $B M \mathcal{F} 1965 ; 1: 350-3$.

41 Greenberg M, Davies TAL. Mesothelioma registe 1967-68. Br f Ind Med 1974;31:91-104.

42 Hirsch A, Brochard P, DeCremoux H, et al. Features of asbestos-exposed and unexposed mesothelioma. $\mathrm{Am} \mathcal{F}$ Ind Med 1982;3:413-22.

43 Law MR, Ward FG, Hodson ME, Heard BE. Evidence for longer survival of patients with pleural mesothelioma without asbestos exposure. Thorax 1983;38:744-6.

44 Lieben J, Pistawka H. Mesothelioma and asbestos exposure. Arch Environ Health 1967;14:559-63.

45 McDonald JC, Armstrong B, Case B, Doell D McGaughey WTE, McDonald AD, Sebastien P. Mesothelioma and asbestos fiber type: evidence from lung tissue analyses. Cancer 1989;63:1544-7.

46 Milne JEH. Thirty-two cases of mesothelioma in Victoria Australia: a retrospective survey related to occupationa asbestos exposure. Br ₹Ind Med 1976;33:115-22.

47 Mowe G, Gylseth B. Occupational exposure and regional variation of malignant mesothelioma in Norway, 1970 79. Am ₹ Ind Med 1986;9:323-32.

48 Newhouse ML, Thompson H. Mesothelioma of pleura and peritoneum following exposure to asbestos in the London area. Br f Ind Med 1965;22:261-9.

49 Oels HC, Harrison EG, Carr DT, Bernatz PE. Diffuse malignant mesothelioma of the pleura: a review of 37 cases. Chest 1971;60:564-70.

50 Rubino GF, Scansetti G, Donna A, Palestro G. Epidemiology of pleural mesothelioma in north-western Italy (Piedmont). Br f Ind Med 1972;29:436-42.

51 Stumphius J. Epidemiology of mesothelioma on Walcheren Island. Br F Ind Med 1971;28:59-66.

52 Tagnon I, Blot WJ, Stroube RB, et al. Mesothelioma associated with the shipbuilding industry in coastal Virginia. Cancer Res 1980;40:3875-9.

53 Theriault GP. Grand-Bois L. Mesothelioma and asbestos in the Province of Quebec, 1969-1972. Arch Env Health 1978;33:15-9.

54 Vianna NJ, Polan AK. Non-occupational exposure to asbestos and malignant mesothelioma in females. Lancet 1978; i: $1061-3$

55 Vogelzang NJ, Schultz SM, Iannucci AM, Kennedy BJ. Malignant mesothelioma: the University of Minnesota experience. Cancer 1984;53:377-83.

56 Wagner JC, Sleggs CA, Marchand P. Diffuse pleural mesothelioma and asbestos exposure in the north western Cape Province. Br ₹Ind Med 1960;17:260-71.

57 Whitwell F, Rawcliffe RM. Diffuse malignant mesothelioma and asbestos exposure. Thorax 1971;26:6-22.

58 Whitwell F, Scott J, Grimshaw M. Relationship between occupations and asbestos-fibre content of the lungs in patients with pleural mesothelioma, lung cancer, and other diseases. Thorax 1977;32:377-86.

59 Wright WE, Sherwin RP, Dickson EA, et al. Malignant mesothelioma: incidence, asbestos exposure, and reclassification of histopathology. $\mathrm{Br} \mathcal{F}$ Ind $\mathrm{Med}$ 1984;41: $39-45$

60 Zielhuis RL, Versteeg JPJ, Plantiejdt HT. Pleural mesothelioma and exposure to asbestos. Int Arch Occup Environ Health $1975 ; 36: 1-18$.

61 Connelly RR, Spirtas R, Myers MH, et al. Demographic patterns for mesothelioma in the United States. F Natl patterns for mesothelioma in

62 Enterline PE, Henderson VL. Geographic patterns for pleural mesothelioma deaths in the United States, 1968-1981. F Natl Cancer Inst 1987;79:31-7.

63 Walker AM, Loughlin JE, Friedlander MS, et al. Projections of asbestos-related disease 1980-2009. f Occup Med 1983;25:409-25.

64 Cicioni C, London SJ, Garabrant DH, et al. Occupational asbestos exposure and mesothelioma risk in Los Angeles County: application of an occupational hazard survey job-exposure matrix. Am $\mathcal{F}$ Ind Med 1991;20:371-9.

65 Coggon D, Pippard EC, Acheson ED. Accuracy of occupational histories obtained from wives. $B r \mathcal{F}$ Ind Med $1985 ; 42: 563-4$.

66 Lerchen ML, Samet JM. An assessment of the validity of questionnaire responses provided by a surviving spouse. Am $\mathcal{f}$ Epidemiol 1986;123:481-9. 